\title{
Dynamic simulation for optimisation solution of manufacturing processes
}

\author{
Vladimíra Schindlerová ${ }^{1, *}$, Ivana Šajdlerová ${ }^{1}$, Dominika Lehocká $^{2}$ \\ ${ }^{1}$ VŠB - Technical University of Ostrava, Faculty of Mechanical Engineering, 17. listopadu 2172/15, \\ 708 33, Ostrava - Poruba, Czech Republic \\ ${ }^{2}$ Technical University of Kosice, Faculty of Manufacturing Technologies with a seat in Presov, \\ Bayerova 1, 08001 Presov, Slovak Republic
}

\begin{abstract}
One way how to study the real behaviour of industrial processes or systems in practice is to use computer simulations. We can simulate different conditions and find optimal parameters without increased risk. The right application of these parameters in practice can produce the desired results. The advantage is not only the safe verification of various variants of the simulated parameters, but also the possibility of their use in different areas of industrial practice. This article deals with an example of the use of simulation in the production of the selected automobile cooling system component. The simulation model was created to design the correct number of Kanban circuits to shorten production lead time and to reduce inter-operational supplies. The suitability of using computer simulations to optimize the production processes and systems in practice can be confirmed based on comparison of the results from the computer simulation with results achieved in practice.
\end{abstract}

Keywords: Dynamic Simulation, Optimisation, Manufacturing Processes, Kanban

\section{Introduction}

Evaluating the quality of delivered products or provided services by customers depends on the degree of fulfilment of the expected requirements whether it is the ability to deliver products or services corresponding to the customers' ideas as for the appearance and design, correct amount, agreed delivery times or required quality at reasonable prices. The current market environment forces the companies to respond to changes and customer demands faster and in a more targeted way. It is necessary to search for suitable solutions in all business processes, minimizing the risk of incorrect decisions. This environment brings large business opportunities on one hand and possible risks on the other. The relatively big and stable interest of the management of the companies is reflected in the modernization of management of process systems, development of new high-quality products and minimization of costs incurred. The simulation systems which can assist in the decision-making processes associated with the design of manufacturing processes and systems are one of the possible solutions [1].

\footnotetext{
* Corresponding author: vladimira.schindlerova@vsb.cz

Reviewers: Peter Demeč, Milan Edl
} 


\section{Methodological base - Kanban, dynamic simulation}

The production pace is determined by the market requirements and it is the task of companies to meet these requirements as much as possible. Currently, various planning and business process management methods are used for the efficient use of available manufacturing resources $[1,2,3]$. The question is, which methods or techniques are the most suitable solution. One of many applicable logistics solutions for smooth flow and shortening of the sequence of individual production processes is the KANBAN method (Japanese term for a label or card).

\subsection{Kanban}

The decentralized organization production system Kanban aims to deliver the material into the manufacturing process at the lowest turnover capital within a certain time frame. When integrating the Kanban system, we have to plan with respect to consistent sequence of the product on the final assembly line, schematic layout of the machinery, standardization of processes, change of production etc. [2]

\subsection{Dynamic simulation}

The simulation is also referred to as a modern method of analysing complex business processes which include the elements of coincidental and dynamic behaviour. It is a very successful method of analysing business processes. The applications in practice have shown that companies which have used the optimisation for their business processes have achieved financial, material and personnel savings. [3,4]

\section{Simulation tools}

In practice, we can encounter various simulation software, examples of some of which are presented in Tab. 1.

Table 1. Setting Word's margins

\begin{tabular}{|l|l|}
\hline MATLAB & $\begin{array}{l}\text { For mathematical purposes, technical fields and disciplines of } \\
\text { economics - MathWorks company [5]. }\end{array}$ \\
\hline ARENA & $\begin{array}{l}\text { General simulation software for industrial applications and } \\
\text { business process re-engineering, graphical animation system, } \\
\text { principles of hierarchical modelling, designated for any } \\
\text { industries - Rockwell Automation company [6]. }\end{array}$ \\
\hline PROMODEL & $\begin{array}{l}\text { Simulation product for prediction in various fields and industries } \\
\text { - industry, army, aviation, health service - Promodel } \\
\text { Corporation [7]. }\end{array}$ \\
\hline SIMPROCESS & $\begin{array}{l}\text { Simulation of company processes, it integrates process mapping, } \\
\text { discrete simulation and activity - based costing - CACI } \\
\text { International Inc. [8]. }\end{array}$ \\
\hline SIMSCRIPT & $\begin{array}{l}\text { Programming language for simulation of projects; simulation and } \\
\text { modelling of applications with interactive graphical user } \\
\text { interface, presentations and 2-D animation of graphics - CACI } \\
\text { International Inc. [8]. }\end{array}$ \\
\hline WITNESS 14, & $\begin{array}{l}\text { Set of tools for modelling and simulation of any company pro- } \\
\text { cesses in various fields and industries - Lanner Group Ltd. [9]. }\end{array}$ \\
\hline SIMNESS Horizon & $\begin{array}{l}\text { Simulation software which can be used by anyone for } \\
\text { visualization, evaluation, and enhancement of processes; } \\
\text { commercial simulation software -SIMUL8 Corporation [10]. }\end{array}$ \\
\hline
\end{tabular}


Computer simulations can be used in numerous practical situations, for example at optimisation of complex production systems, including logistic ones, scheduling of production, forecasting of prices on financial markets, as process tools for engineering simulation, municipal simulation models and traffic engineering, simulation of behaviour of structures under various conditions, meteorological forecasts, project management, risk management, etc.

Use of simulation software in company practice has numerous advantages:

- it is possible to simulate without an intervention into real operation;

- it is also possible to experiment with situations which could not be tested in real conditions;

- simulation offers more comprehensive view of the resolved problem and leads to better understanding of the real system;

- simulation offers broader overview of company processes;

- it is possible to resolve even very complex systems that cannot be resolved by analytical methods;

- several different variants of solution can be verified relatively quickly;

- it is possible to investigate behaviour of the system in real, accelerated or decelerated time;

- it is possible to find or to verify real functioning of the system in contrast to suppositions and guesses of individuals. [1].

Difficult interpretation of the results of some simulation tasks is a disadvantage of the simulation, as well as the fact that they are often highly time consuming or expensive and require knowledge and experience of the workers with creation of models and knowledge of work with the simulation software.

Below, we will show an example of successful simulation in practice implemented with the use of the WITNESS simulation software. The WITNESS simulation tool is a tool used for simulating and optimising manufacturing, logistics and servicing systems. It is produced by Lanner Group Ltd. The advantage of the system is its use which is based on interactive simulation of systems of certain events introduced in the organization using physical elements depending on the timeline. [8]

\section{Example of practical application}

The company needed to design a number of Kanban circuits to shorten production lead time and reduce in-process inventory. [10]

The aim of the enterprise was the application of the Kanban system using a computer simulation in a particular case of automobile cooling system production which points out to a $90 \%$ reduction in stock inventory of semi-finished products, helps to a fast transmission of information and increase of flexibility of all workplaces.

Analysis of the current state revealed the following facts:

- the company works in three-shift operation; one shift lasts 480 minutes;

- 1750 pcs of final products are produced daily (automobile cooling system components);

- components A and B are parts of the product;

- the company working breaks in total represent 45 minutes of working time per work;

- the time of one working cycle of the workplace includes the time necessary to operate the machine, move the finished product to the next operation and insert a new product into the machine;

- batches of $50 \mathrm{pcs}$ are degreased $(260 \mathrm{sec}=4.3333 \mathrm{~min})$; 
- after degreasing, there are again 1750 pieces of the A and B manufacturing segments in each buffer. Subsequently, one after the other according to the type, they are taken from the buffers and inserted into the $\mathrm{CNC}$ machine;

- conveyor belts move at $5 \mathrm{~m} / \mathrm{min}$;

- the assembly is the further step in the technological process. The machined input components $\mathrm{A}$ and $\mathrm{B}$ are transformed into the resulting products;

- current production time for $1750 \mathrm{pcs}=2486.3 \mathrm{~min}$.

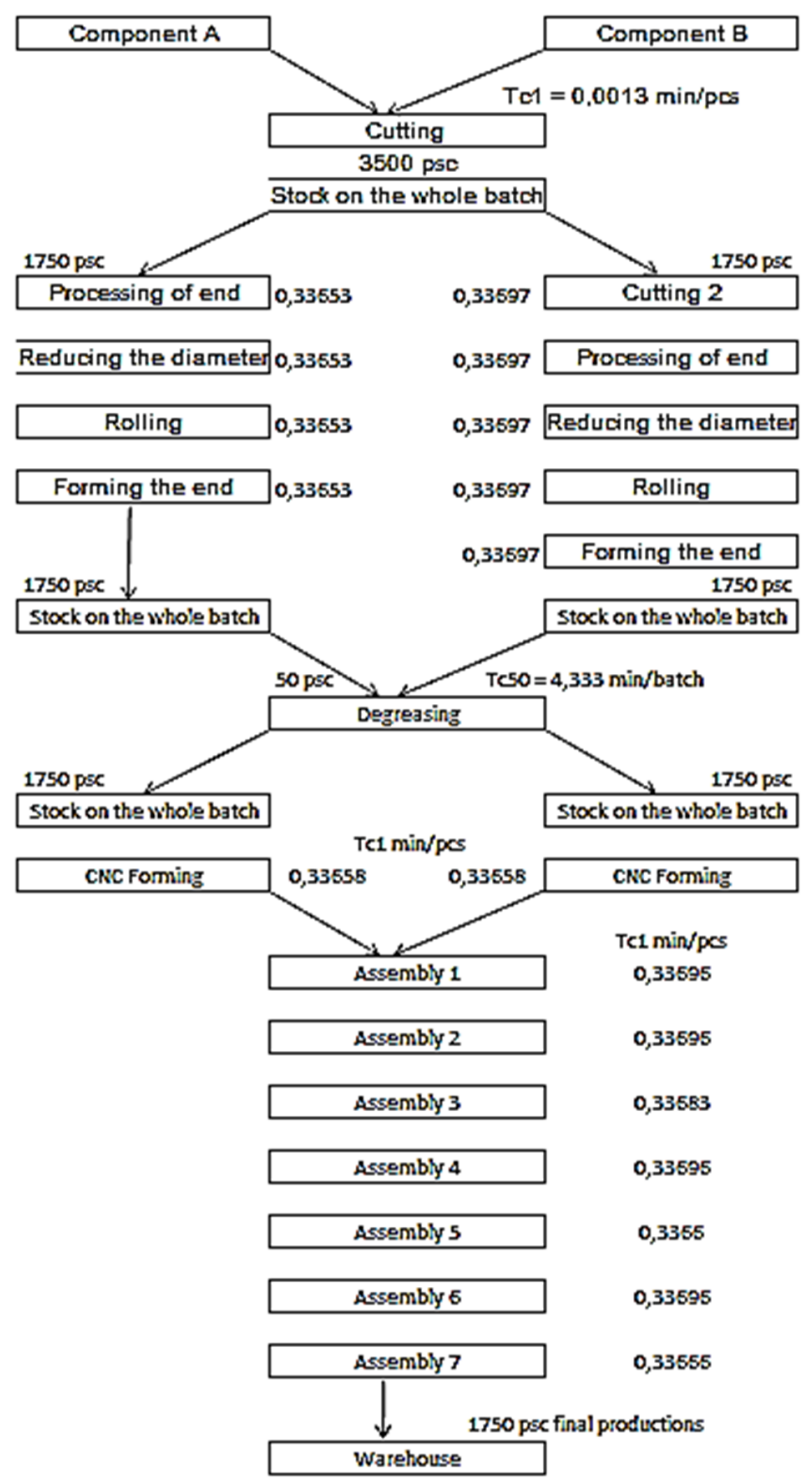

Fig. 1. Current state (scheme of the automobile cooling circuit production process) 
The procedure for the simulation of the production model of the automobile cooling circuit was determined in the following steps:

- assembly of the original variant using simulation elements;

- determination of process times, including service times, among particular workplaces;

- defining the logistics flow of the material and its amount;

- assigning workers to single-purpose machines;

- starting the simulation run (simulation is done in minutes).

The simulation defined by the Witness software works on the principle of monitoring the used elements and their acting in the simulation model which is created by the basic used elements on the basis of a real manufacturing system.

Diagram of the model was plotted using the elements from the WITNESS library (Fig. 2).

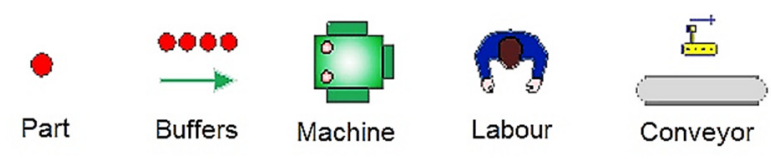

Fig. 2. Elements used for creation of the simulation model. [8]

- Element "Part"- represents the A and B components passing through the manufacturing model.

- Element "Buffers"- represents the containers or rather the storage places for unfinished production or warehouses with finally finished products. They are very important for the Kanban system application since they determine the size of inter-operational supplies.

- Element "Machine" - represents the single-purpose machines in the simulation which are used in the manufacturing process of the automobile cooling system. The machines are simulated using real parameters.

- Element "Labour", represents a worker who has the task of operating the production machine and storing the components in prepared buffers with semi-finished products.

- Element "Conveyor" - conveyor. In particular, it is a conveyor belt for transporting the material in the last stage of production, which involves the assembly of the A and B components in one unit.

Once all known parameters have been set, the model is run in the simulation program to find out the current total production time of the product which is $2486,3 \mathrm{~min}$ for the required 1750 pcs. Figure 3 shows the model of the current state of the automobile cooling system production.

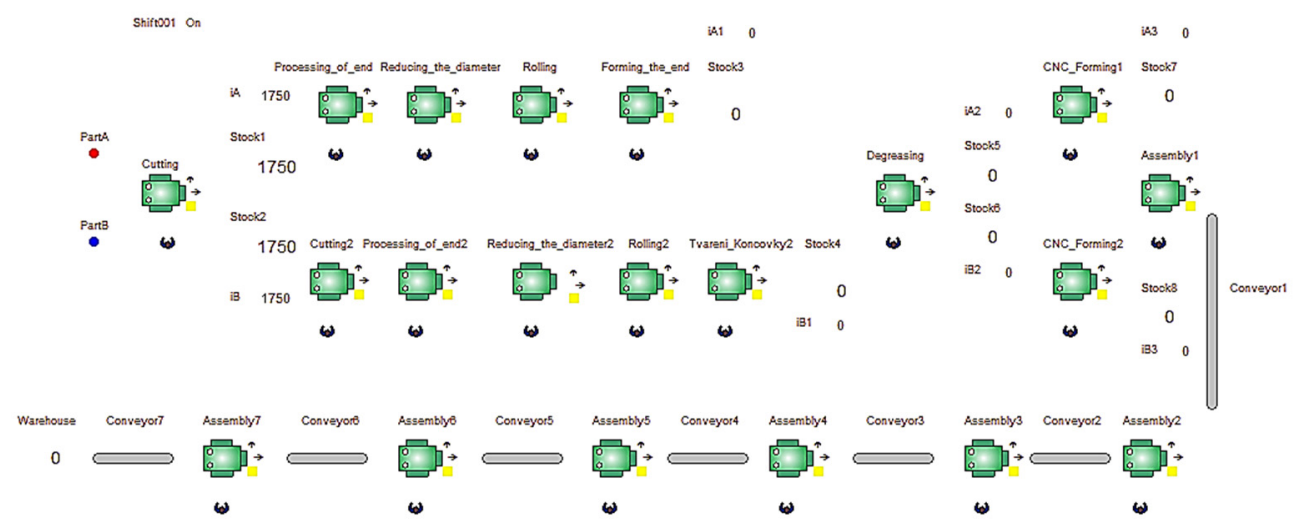

Fig. 3. Diagram of the current state of WITNESS 


\section{Results obtained by the simulation}

As a part of the simulation, variants were created for forming the Kanban circuits with regard to the increase of the company efficiency in terms of production times and operational stocks which entail increased costs. The proposed variants of the Kanban circuits were elaborated in the Witness simulation program and subsequently, they were evaluated and compared with the model of the current state in the company. The results of particular variants are presented in Table 2.

Table 2. Simulation results of particular Kanban circuits

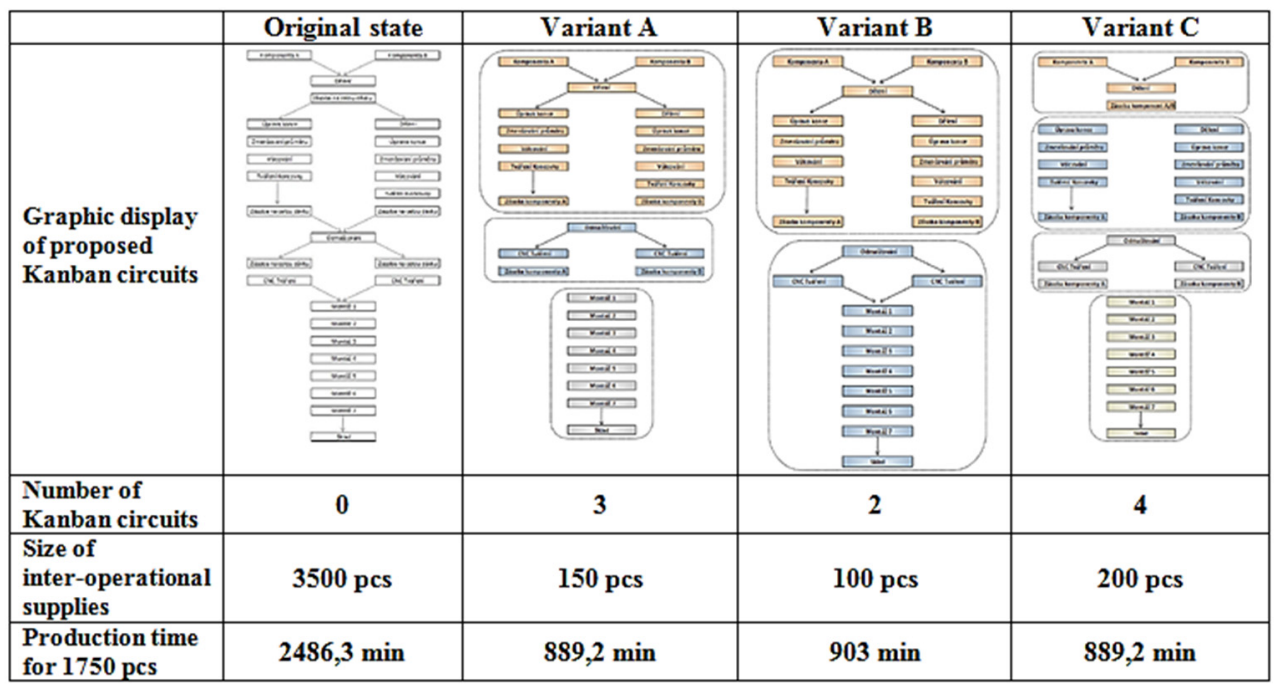

The optimal choice of the most suitable variant always depends on what becomes the priority. In terms of the production time, variants $\mathrm{A}$ and $\mathrm{C}$ are comparable. In case of the size of inter-operational supplies, variant B seems to be optimal. The choice of the most suitable variant depends on the priorities of the manufacturing company.

\section{Conclusion}

The paper deals with the issues of the use of simulation of company processes in practice. Simulations are one of the possibilities how to verify the envisaged changes in the production process without any bigger risk, or how to set optimal conditions of the system. We simulated on a practical example from design a number of Kanban circuits to shorten production lead time and reduce in-process inventory.

Simulations include a huge advantage when compared with real systems, they enable experiments and have a significant degree of variability and repeatability. Dynamic simulations have a great potential as for the extent and possibilities of use. They can not only be used in the design and optimization of production processes but they can also offer an interesting solution for planning and production management due to their properties. Simulations are one of the ways to verify the proposed changes in the production process or to set optimal system conditions without any bigger risk.

The case study was focused on the simulation of KANBAN circuits for the production of components for automobile cooling systems. It has been proved that the practical use of the simulation model based on a real production process enables to verify the possibility of 
KANBAN circuit settings and thus highly reliably plan the optimal use of production equipment and increase the throughput of the manufacturing system.

By using this model, which allows tracking the inputs as well as the degree of completion of individual products, the company can interactively use the proposed production planning model.

The model is designed to be able to correspond with computer outputs so that each product could be assigned to his technological processing, created in several input variants into the manufacturing section and so that the most suitable variant could be chosen.

\section{References}

1. R. E. Shannon, J.J. Swain, D. Goldsman, R.C. Crain, J. R. Wilson, Introduction to Simulation. Proceedings of the 1992 Winter Simulation Conference, Virginia USA, 6573 (1992)

2. I. Mašín, M. Vytlačil, (1996). Way to higher productivity: strategy based on industrial engineering. Liberec: Institute of Industrial Engineering, (1996)

3. A.M. Law, Simulation modeling and analysis. 4th ed., New York: McGraw-Hill, 2007

4. V. Schindlerová, I. Šajdlerová, P. Mohyla, Optimization of metallurgical processes using dynamic simulation. METAL 2016, Conference Proceedings, TANGER Ltd, 2013-2018 (2016)

5. MathWorks - MATLAB and Simulink for Technical Computing, (C) 1994-2018 The MathWorks, Inc.) Available: http://www.mathworks.com/

6. Arena Simulation (Software by Rockwell Automation: Products, (C) 2018 Rockwell Automation) Available: http://www.arenasimulation.com/

7. ProModel - Technology Enabled Predictive Analytics Simulation (C) 2018 ProModel Corporation) Available: http://www.promodel.com/

8. CACI Profile (online). (C) 2018 CACI International) Available: http://www.caci.com

9. WITNESS: Witness. (Witness (C) 2018). Available: http://witness.cz

10. SIMUL8 Simulation Software - For Visual Process Simulation Modeling. (C) 2018 SIMUL8 Corporation.) Available: http://www.simul8.com

11. L. Žilt, Record Keeping and Identification of Metallurgical Materials: Diploma Thesis. VSB - TUO, Faculty of Mechanical Engineering, Department of Mechanical Technology, (2016) 